\title{
DOES TRANSLATION (EX)CHANGE EVERYTHING? A FRAMEWORK FOR POLITICAL TRANSLATION
}

\author{
Titela VÎLCEANU* \\ University of Craiova, Romania
}

\begin{abstract}
The paper focuses on the translation of the political discourse, embedding linguistic and cross-cultural perspectives. The choice is motivated by the fact that in the first decades of the new millenium we have witnessed an exponential increase in the quantity, quality and urgency of this discourse within the international political sphere. The political discourse can be said to unearthen the hidden agenda of the contemporary large-scale crises: the financial crisis, shifts of power, terrorist attacks, etc. In this light, the question arises: Does translation objectively and accurately reflect the strategies in the discourse of political leaders, and the problematisation of supranational identities such as the European one (more specifically, referring to membership to the European Union)? Answers to such questions are attempted starting from the premise that the translation of the political discourse or political translation (Trosborg, 1997; Biel, 2017) is an emerging sub-type of institutional translation struggling to assert its own identity.
\end{abstract}

Keywords: political discourse; political translation; hiding and highlighting strategies.

\section{SETTING THE SCENE. TRIANGULATING POLITICAL LINGUISTICS}

The long-held recognition of the genuine co-evolution of language and politics goes back to classical Greek and Roman rhetoric - Aristotle and Cicero being two prominent names in this respect, claiming that the art of public speaking is the key to (active) citizenship, as indicated by Aristotle’s “politikon zoon”from a descriptive perspective. The threefold distinction that Aristotle operates with respect to rhetoric genres, namely deliberative, forensic and epideictic, underpins a different target audience, time-orientation and objectives. Priority is given to decision-making in public affairs (to exhort or deter from a course of action), ethical/legal issues (defend or condemn someone's actions) and ceremonial settings (to praise or discredit somebody), respectively. This is yet

*elavilceanu@yahoo.com 
another living proof that language is not placed in a social and political vacuum, on the contrary it fulfils complex functions. Furthermore, the deep-seated western philosophical tradition (notably, Plato) enshrines the active power of language in the political state, based on a normative approach.

Taking a leap in time, we ascertain the ever increasing importance of socially-oriented fields of knowledge and practices, as well as the emergence of an array of disciplines concerned with the relationship between language and power, such as Critical Discourse Analysis (Fairclough 1995; Wodak and Chilton 2005), Political Discourse Analysis (PDA) (van Dijk 1997; Chilton 2004; Fairclough and Faiclough 2012), Analysis of Political Discourse (APD) (Okulska and Cap 2010), Political Linguistics (PL) (Blommaert and Bulcaen 1997), etc. We prefer the last term in view of its all-inclusive nature; it suggests the idea of an outward looking discipline and reflects the nature and functions of political discourse, alongside the many interfaces between the study of language and language practices within political contexts and beyond. This dynamic contextualisation and renewed critical awareness brings to the fore not only the actions and language practices of professional politicians and institutions, but those of the citizens as language users undertaking accommodation work (in pragmatic terms) for real-life purposes, ordinary language being thus infiltrated, to a large extent, by terms from institutionalized politics. In our opinion, political linguistics is able to make a full use of the explanatory power of both linguistic and non-linguistic concepts available to different actors on the political scene, professionals (politicians and political parties, lobbyists and pressure groups) and lay population (citizenry) alike.

Chilton (2004) dwells on the relationship between language and politics from a cognitive and evolutionary perspective, providing insights into the ways in which actors represent (and present) reality and into the fact that politics is prevailingly a linguistic arena. The author does not envisage political discourse as fundamentally argumentative and deliberative in nature, linking representation to deliberation and action and further developing the languageethics interface. Politics and political studies are concerned with two seemingly opposing stances: on the one hand, the struggle for power,on the other the cooperation to resolve clashes of interest, reflected in language by noncooperation and cooperation strategies of communication.

We also plead for a blended approach to the political discourse, both descriptive and normative, in line with Chilton and Schäffner, in an attempt to define the scope and specificities of political linguistics: "What is distinctive about the linguistic and discourse-based approach to politics, however, is that it adduces a specific kind of empirical evidence, a kind so obvious that it is ignored in political science and even in political philosophy, except to the extent that the latter is interested in political concepts and their linguistic expression. (8) 
Various interdisciplinary, methodological and source-specific approaches should be combined to examine such a dynamic discourse phenomenon in order to comprehensively and accurately identify and describe the underlying mechanisms and contexts which make it possible for actors to exert their agency and linguistically empower them to impact on the world.

In a corollary way, this question is related to the need to define politics and political linguistics as broad, multilayered and fuzzy-edge fields, encompassing more than institutional politics and monologic or dialogic political speeches (parliamentary debates, party conferences, statements, propaganda, etc.), therefore incorporating everyday politics and politically correct language, too.

\section{THE EU DISCOURSE IN BRIEF}

Mainstream literature features the political discourse as both internally (from the micro-textual perspective) and externally (from a macro-perspective) complex on account of its anchoring in communicative and rhetorical contexts of situation and in historically and culturally conditioned concepts and norms. To narrow focus, we shall discuss the EU discourse, understood as both discourse about the $\mathrm{EU}$ and discourse in the making within the EU.

Our endeavour is premised by the idea that the EU discourse shaping and use is not only achieved through specific terminology (encompassing technical, bureaucratic or political terms, many of which have been coined in the past decades), but also through a broader set of complex linguistic devices (among which, ambiguity, vagueness, extensive use of collective nouns, personal pronouns, metaphor, metonymy, etc.). We are equally interested in the various types of hidden interaction in order to uncover implicitness and detect the intended meaning, as well as the diversity (in unity) of voices (as markers of polyphony). Additionally, the situational and rhetorical complexities are explained by the challenges the variety of public spheres and institutions, multiple audiences, traditional and new media within which the EU discoursetakes place or to which it relates. This discourse results from different deliberative processes - policies, legislation, administrative measures, , guidelines, etc, - whereas peripheral political messages are instantiated in press conferences and releases, memos, reports, commentaries, talks, bureaucratic procedures, institutuional websites, etc. Once again, we envisage situated discourse and we aim at an analytical balance between text and context, especially because we understand discourse as text in context within an interdisciplinary landscape. On the other hand, we acknowledge interdiscursivity due to the overlapping nature of texts, explained by the factors governing decision-making and production of EU policy documents, likely to engender 
ownership of meanings and interpretations of a common European identity, discursively co-constructed in interaction

Such complex endeavour is aptly described by Strömbäck (2010) who distinguishes between "mediated politics" and "mediatised politics"; in the same climate of opinion, Fetzer (2013) warns us against losing the ability to detect the soft and mundane aspects of political language use, and Fløttum (2013) is concerned with managing hybridity and with the dynamics of mass communication driven by the power of the media to strategically select and deliver political messages in the public sphere. Actually, we are witnessing a process of "communicative constructivism" - in Habermas' terms (2006) - since the everyday meaning of the multilingual European society (generically and consistently referred to by the term "Europe") is generated and articulated in ongoing communication flows in English (most likely leading to a kind of hegemonic multilingualism sine English is the procedural language - see, for instance Biel, 2017). Political language is therefore linked to human behaviour and becomes instrumental to interconnectivity.

The process of Europenisation is assimilated to communication patterns at the transnational level and to a European culture of political discourse, comprising four more or less overlapping dimensions, according to Hepp (2016): "Europeanisation by vertical transnational connectivity" - referring to "communicative linkages between the national and the European level," for instance, through media coverage (Koopmans and Statham 38); "Europeanisation by horizontal transnational connectivity" - involving "communicative linkages between different member states" through mutual observation and mutual discursive exchange, online forums, etc. (Koopmans and Statham38); "Europeanisation by transnationally converging discourse"(Wessler et al. 11ff) via shared frames of media coverage; "Europeanisation by transnational collective belonging" as European in-group membership and a prepotent identity in the form of an active European community of speech/communication or a European public sphere.

\section{POLITICAL TRANSLATION: SPEAKING TO/OF EUROPE}

The unquestioned institutional ascendancy of English and the unprecedented need for language services, fuelled by globalisation, technological progess and demographic movements explains the current ideology and axiology of translation frameworks and practices, as well as the proliferation of hybrid genres and operative texts, i.e. specific discourses and interference zones.

The shaping force of translationhas been acknowledged by translation theorists and various other scholars (among which sociologists, cultural anthropologists, pragmaticists, political scientists, etc.), by the professional 
translators themselves who have grown more aware of their status as mediators in intercultural communication, impacting on almost every arena of the social and (geo)political life, and, last but not least, by policy makers, too. With respect to the translator's status it should be noticed that, paradoxically, the role of translators becomes much more visible with their faulty performance rather than with with error-free target text production, and, depending on context, less competent translators will bear the burden for the mismatches between the source text and the target text, to say the least.

(Re-)entextualisation, defined as the uprooting of a text from its context of performance and its re- enactment in a context that is foreign to it is taken over by House (2006), who raises the question of the way in which the translator can activate contextual connections and link the target text to the old context (best featuring the source text production and reception) and its new context the process is widely known as re-contextualisation.

It is advisable and feasible not to separate discourse from socio-cultural or ideological accounts of translation because it reveals a particular stance and lines of action and may prove to be the essential link between texture (i.e., the surface of text) and what is socially enacted by translation (i.e., in the deep structure). Hiding and highlighting become versatile notions with reference to translation as the contextual meaning of the translated text is determined by a constellation of endogenous and exogenous factors. Among the key ones, we mention institutional power (little exercised by the translator) and interactional power (where the translator's decision making is more visible).

In what follows, we shall discuss the translation of the political discourse or political translation (notably, Trosborg, 1997; Biel, 2017) as an emerging sub-type of institutional translation struggling to assert its own identity. In the first decades of the new millenium we have witnessed an exponential increase in the quantity, quality and urgency of the discourse within the international political sphere, and the political discourse can be said to unearthen the hidden agenda of the contemporary issues of widespread concern: the financial crisis, shifts of power, terrorist attacks, etc. Under the circumstances, the question arises: Does translation objectively and accurately reflect the strategies in the discourse of political leaders, and the problematisation of supra- or transnational identities such as the European one (more specifically, referring to membership to the European Union)?

One possible answer lies in Mason's claim that there is "little uniformity of practice or evidence of influence of institutional guidelines on translator behaviour" (2004: 481) at the European Parliament, resulting in discoursal shifts, equated to toning down or intensifying the message conveyed in the original text. Mason highlights the political translator's visibility from a processand product oriented perspective, playing an active role in the shaping of institutional(ised) discourses while implicitly discarding mechanistic mediation 
practices. We fully agree and add that a pre-requisite for a process- and product outlook on the political is that it represents an open and interactive system made up of linguistic, social, socio-cultural and cognitive contexts. Therefore, political translation is not a clear-cut domain and becomes more and more hybrid, intersecting, conceptually and methodologically, with other long-established fields (for instance, literary translation from which it transfers the concern for authorship and a text-centred approach) or newly emerged sub-fields (journalistic translation, media translation, as more user-centred, focusing on meeting the (end) users' needs and expectations and on measuring the degree of this match, from the point of view of usability, etc.). Equally, we have to acknowledge the growing strand of a translator-centred approach enhancing recognition of the importance of the profession and of the translator's role not only in mediating communication across cultures but also in shaping the society we live in. In this order of ideas, Chesterman (2009) advocates an extension of Translation Studies so as to incorporate "Translator Studies”, based on empirical and ethical grounds:translators do reflect on the cultural, ethical, and political issues raised by their work and act according not only to the prevailing ideology, but also to their beliefs and professional code of conduct.

Although contemporary Translation Studies has increasingly focused on investigating the factors that systematically govern the production and disseminationof translated political discourse,the translational practices in the fields of politics have not yet been sufficiently investigated. Discursive events in the domain of international politics, such as state visits, joint press conferences, and jointly produced policy statements, are highly complex events. Moreover, these discursive events and the resulting texts are recontextualised via the channels of the political institutions themselves and via mass media. One special mention here concerns the fact that political texts are primarily drafted in English at the EU and that we expect the translated version to be heavily influenced by the corresponding stylistical conventions in English on account of the ascendancy of English as a lingua franca and of temporal constraints (enforced deadlines for text production/translation delivery). Therefore, in line with Halverson, we dissociate from traditional approaches to translation that maintained "a focus on the (two) linguistic/semiotic/discourse systems involved in translation, with a particular emphasis on strategies for coping with system differences" (120) and favour a text- based perspective, considering the textual patterns and discourse practices as "instantiations of the potential inherent in the system.”

The still incipient political translation research has identified a number of text-centred stances, whereas other studies are dedicated to translation censorhip; however translation policies at supra- and transnational levels have been rarely addressed. Naturally, such granularity or fragmentation could not 
have resulted in a viable unitary framework for political translation and efforts need to intensify with a view to achieving this, according to Sárosi-Márdirosz:

The enlarged perspectives and the application of the results of other domains help researchers to prove that translation is not just the expression in the target language of what has been expressed in the source language (preserving semantic and stylistic equivalences), but a more creative activity that enriches the source text with new ideological and cultural features. (160)

Biel (2017) undertakes a structured and systematic analysis and successfully attempts to merge normative, descriptive and functional approaches to political translation highlighting two dimensions which are prioritized in the EU institutions' translation policies and practices:, equivalence (securing referential accuracy and external coherence, i.e. consistency in relation to higher ranking texts/discoursal features ) and textual fit (equated to naturalness and readability).

\section{CONCLUSIONS AND WAYS FORWARD}

To our best knowledge, there is no specialised journal or professional association dedicated to political translation - in order to accurately scope it and boost the profile of this sub-field struggling to gain wider acceptance,rescuing it from its derivative status since it is not inherently less important than any other type of specialised translation. Nor is there a forum or platform for joining scholarly and economic efforts in this direction so as to provide insightful perspectives and achieve a unified theory and a common framework through the dissemination and cross-fertilisation of ideas and best practices.

We admit that the genuine challenge lies in the fact that even the hyperordinate field of Translation Studies is a relatively new discipline in itself scholars agree on 1972 as its birthdate with Holmes' paper "The Name and Nature of Translation Studies" delivered at the $3{ }^{\text {rd }}$ International Conference of Applied Linguistics in Copenhagen. More than four decades old now, Translation Studies still has a blurred status, explained by Brems, Meylaerts and Doorslaer in terms of its hybrid nature and constant transfers from and, more recently, to other fields: "Translation Studies continues to produce a large number of publications dealing with the struggle of defining itself and its object, with the borderlines of both the discipline and the object, with ways of interacting with related (sub)disciplines" (1).

The rigid compartimentalisation of sciences or "disciplinary heredity" (Cohen and Lloyd, 2014) as shaped by specific research methodologies and epistemologies belong to by-gone eras. It has become a fact that the fluidity of 
the twnety-first century scholarship favours inter-, multi- and transdisciplinary research as a dynamic and creative force. And it will continue to do so in the foresseable future. Political translation is no exception to this trend.

Admittedly, the sub-discipline of political translation should be able to provide the framework of principles, rules, hints for translating political texts and for evaluating translations as a background for problem solving. Besides, any theoretical framework should deal with recurrent translation problems and should formulate a set of strategies for approaching these, i.e. it should provide a model whose cohesive character is explained by the collection and interpretation of data. Political translation (theory and practice) should be viewed as neither self-reflexive nor an innocent phenomenological perception of the process of translation; it should aim to the harmonisation of translation principles and strategies in order to enhance a dynamic and flexible system of equivalences. The political translator should be able to accommodate content and form and rely on re-usables to be efficient and effective. Seen in this light, political translation theory goes hand in hand with translation methodology with a view to identifying general and particular problems, being both an applied and interrelated discipline, an eclectic one, drawing its material from various sources. Translation strategies and solutions should be continuously re-evaluated according to the translator's accumulated know-how and via the capitalisation of expertise.

Methodologically speaking, I acknowledge this eclectism in the productive assimilation of descriptive-empirical, normative, critical and functional perspectives on political translation as process and product. Likewise, its versatile, dynamic nature, shaped by coopetition (or cooperative competition) in a flexible kaleidoscopical framework should be emphasised.

In conclusion, we hope that we have managed to draw attention to the more or less systematic ways in which key concepts and methodological approaches to political translation have been developing and creating borderlands, understood as zones of mutual exploration and co-creative spaces. We have every confidence that relatively new directions such as translatorcentred orientations will gain momentum and become institutionalised across a larger number of professional communities and countries. Furthermore, translation, language sciences, social sciences and political sciences having already established their status of sciences in action, increasingly producing texts and contexts across linguistic and cultural barriers, will better inform (mesoinstitutional and macro-societal) practices. Of course, further quantitative and qualitative research, mapping the realities of the market, is necessary to generate a high profile of a new scientific field, and claims must be supported by reliable direct and indirect evidence in order to demonstrate effectiveness, scale, quality and importance of achievements. 


\section{Works Cited}

Biel, Łucja. "Quality in Institutional EU Translation: Parameters, Policies and Practices”. Quality Aspects in Institutional Translation. Eds. Tomáš Svoboda , Łucja Biel, Krzysztof Łoboda. Berlin: Language Science Press. 2017. pp. 3157. DOI:10.5281/zenodo.1048183.

Blommaert, Jan, Bulcaen, Chris, eds. Political Linguistics. Amsterdam/Philadelphia: John Benjamins Publishing Company, 1997. Print.

Chesterman, Andrew. "The name and nature of translator studies". Hermes - Journal of Language and Communication 42, 2009. pp. 13-22. Print.

Chilton, Paul, Schäffner, Cristina, eds. Politics as Text and Talk. Analytic Approaches to Political Discourse. Amsterdam/Philadelphia: John Benjamins Publishing Company, 2002. Print.

Chilton, Paul. Analysing Political Disourse. Theory and Practice. London and New York: Routledge, 2004. Print.

Cohen, Eli B., Lloyd, Scott. "Disciplinary Evolution and the Rise of the Transdiscipline”. Informing Science: The International Journal of an Emerging Transdiscipline, 17, 2014. pp. 189-215. Print.

Fairclough, Norman. CriticalDiscourse Analysis. Boston: Addison Wesley, 1995. Print.

Fairclough, Isabela, Fairclough, Norman. Political Discourse Analysis. A Method for Advanced Students. London and New York: Routledge, 2012. Print.

Fetzer, Anita. "The multilayered and multifaceted nature of political discourse". The Pragmatics of Political Discourse. Ed. Anita Fetzer. Amsterdam/Philadelphia: John Benjamins Publishing Company, 2013. pp. 1-21. Print.

Fløttum, Kjersti. "Speaking of and within the EU - Introduction”. Speaking of Europe. Approaches to Complexity in European Political Discourse.Ed. Kjersti Fløttum. Amsterdam/Philadelphia: John Benjamins Publishing Company, 2013. pp. 1-19. Print.

Habermas, Jürgen. "Political Communication in Media Society: Does Democracy Still Enjoy an Epistemic Dimension? The Impact of Normative Theory on Empirical Research”. Communication Theory 16, 2006. pp. 411-426. Print.

Halverson, Sandra. "Reorienting Translation Studies: Cognitive Approaches and the Centrality of the Translator". Translation: A Multidisciplinary Approach. Ed. Juliane House, 2014. Hampshire: Palgrave MacMillan, pp.117-139. Print.

Hepp, A. et al. The Communicative Construction of Europe. Cultures of Political Discourse, Public Sphere and the Euro Crisis. Hampshire: Palgrave MacMillan, 2016. Print.

House, Juliane. “Text and Context in Translation”. Journal of Pragmatics, 38, 3. 2006. pp. 338-358. Print.

Koopmans, Ruud, Statham, Paul. "Theoretical Framework, Research Design, and Methods". The Making of a European Public Sphere. Media Discourse and Political Contention. Eds. Ruud Koopmans, Paul Statham. Cambridge: Cambridge University Press, 2010, pp. 34-59. Print.

Mason, Ian. "Text parameters in translation: transitivity and institutional cultures". The Translation Studies Reader. Ed. Lawrence Venuti, 2004. London and New York: Routledge, pp. 470-481. Print. 
Okulska, Urszula, Cap, Piotr. Perspectives in Politics and Discourse. Amsterdam/Philadelphia: John Benjamins Publishing Company, 2010. Print.

Sárosi-Márdirosz, Krisztina. "Problems Related to the Translation of Political Texts". Acta Universitatis Sapientiae, Philologica, 6, 2. 2014. pp. 159-180. DOI: https://doi.org/10.1515/ausp-2015-0012.

Strömbäck, Jesper. "Mediatization of Politics: towards a conceptual framework for comparative research." Sourcebook for Political Communication Research: methods, measures, and analytical techniques. Eds. Erik P. Bucy and R. Lance Holbert. New York: Routledge, 2010. pp. 367-382. Print.

Trosborg, Anna. “Translating Hybrid Political Texts”. Text Typology and Translation. Ed. Anna Trosborg. Amsterdam/Philadelphia: John Benjamins Publishing Company, pp. 1145-158. 2017. Print.

van Dijk, Teun A. "What is Political Discourse Analysis?”. Political Linguistics. Eds. Jan Blommaert and Chris Bulcaen. Amsterdam/Philadelphia: John Benjamins Publishing Company, 1997. pp. 11-52. Print.

Wessler, Hartmut et al. Transnationalization of public spheres. Basingstoke: Palgrave Macmillan, 2008. Print.

Wodak, Ruth, Chilton, Paul, eds. A New Agenda in (Critical) Discourse Analysis. Amsterdam/Philadelphia: John Benjamins Publishing Company, 2005. Print. 